\title{
A Cauda Longa e o jornalismo Como a teoria da Cauda Longa se aplica no jornalismo
}

\author{
Valdenise Schmitt ${ }^{1}$ \\ UFSC \\ Francisco Antonio Pereira Fialho² \\ UFSC
}

\begin{abstract}
Resumo: A Internet produziu transformações e oportunidades. Este artigo explica a teoria da Cauda Longa e como ela se aplica no jornalismo. Duas caudas longas estão transformando o jornalismo, uma relacionada à troca dos valores-notícia através do tempo e, a outra, ao crescente número de blogs que, coletivamente, estão competindo com a mídia tradicional pela atenção dos leitores. $O$ cenário atual indica que apesar do modelo tradicional emissor-receptor ter sido rompido, a função do jornalista não será extinta, uma vez que cabe a este profissional o papel de seleção e de análise dos acontecimentos relevantes que devem ser divulgados. Além disso, indica que no futuro os meios de comunicação social devem seguir o modelo comunicativo baseado na participação do usuário.
\end{abstract}

Palavras chave: Cauda Longa. Jornalismo. Internet.

Abstract: The Internet produced transformations and chances. This article explains the theory of the Long Tail and how it applies to journalism. Two long tails are transforming the journalism, one related to the exchange of the value of stories over time and, to another one, the increasing number of blogs that, collectively, they are competing with the traditional media for the attention of the readers. The current scene indicates that although the traditional model sender-receiver to have been breached, the function of the journalist will not be extinct, a time that fits to this professional the election paper and of analysis of the important events that must be divulged. Moreover, it indicates that in the future the social media must follow the established communicative model in the participation of the user.

Key words: The long Tail. Journalism. Internet.

1 Jornalista; Especialista em Desenvolvimento de Aplicações Web; Especialista em Novas Mídias, Rádio e TV, Mestre em Engenharia e Gestão do Conhecimento; aluna de Doutorado do Programa Pós-Graduação em Engenharia e Gestão do Conhecimento da Universidade Federal de Santa Catarina (UFSC).

2 Engenheiro Elétrico; Psicólogo; Mestre em Engenharia de Produção; Doutor em Engenharia de Produção. Atualmente é professor associado da Universidade Federal de Santa Catarina. Tem experiência na área de Engenharia e Gestão do Conhecimento, atuando principalmente nos seguintes temas: engenharia do conhecimento, mídias do conhecimento, eco-ergonomia, gestão do conhecimento e ergonomia cognitiva. 


\section{INTRODUÇÃO}

Embora o termo The Long Tail (Cauda Longa), seja comum em textos estatísticos, seu uso popular deve-se a Chris Anderson (STEVENS; RIVASRODRIGUES, 2007). Em 2004, Anderson utilizou o termo na revista Wired para se referir, sob uma perspectiva genérica, a economia da abundância - "o que acontece quando os gargalos que se interpõem entre a oferta e a demanda em nossa cultura começam a desaparecer e tudo se torna disponível para todos." (ANDERSON, 2006, p. 11).

Este cenário está sendo construído em grande parte pela Internet e pelas novas tecnologias. A Internet transformou o mercado de massa em milhões de mercados de nicho (ANDERSON, 2006). No campo da comunicação, seu impacto, segundo Gillmor (2004), só é comparável ao aparecimento da imprensa de Gutenberg.

Enquanto a imprensa tirou das mãos dos monges do Vaticano o controle editorial (GILMOR, 2004), a Internet converteu todos os cidadãos em distribuidores de conteúdo (ANDERSON, 2006). Com isso, "os meios de comunicação social deixaram de ter exclusividade de publicação e a audiência passou também a ter esse poder" (RODRIGUES, 2006, p. 64).

A abundância de sites de informação "amadores" fez com que a circulação de jornais caísse mais de um terço em relação ao pico da década de 1980. Este fato, para Anderson (2006, p. 183), "é a prova mais concreta do efeito revolucionário que a Cauda Longa é capaz de exercer sobre as indústrias tradicionais.”

Com a Internet, o poder da imprensa que antes decorria do controle das ferramentas de produção, passou de repente a pertencer a qualquer pessoa com um computador e conexão a Internet (CASTELLS, 2005; ANDERSON, 2006).

Neste contexto, a antiga máxima da mídia americana, a liberdade de imprensa pertence aos que detêm a imprensa, na nova era da mídia digital não faz muito sentido, visto que qualquer pessoa pode produzir, editar e distribuir conteúdo (GILLMOR, 2006). 
Hoje, pode-se dizer que os meios de comunicação social não competem mais entre si: a Folha de São Paulo não concorre só com os demais jornais de São Paulo e de outros lugares, "mas também com a sabedoria coletiva e com a diversidade de informações de todo o mundo on-line.” (ANDERSON, 2006, p. 186)

Por isso, há de se concordar que a Internet é mais que uma tecnologia, é um meio de comunicação, de interação e de organização social (CASTELLS, 2005). Ou definida de outra forma, é um sistema de comunicação global, mais disperso por todo o globo que os sistemas anteriores, e inerentemente bidirecional e ingovernável pelas estruturas políticas existentes (POSTER, 2005).

Este artigo tem como propósito apresentar a teoria da Cauda Longa e utilizála para descrever as mudanças provocadas pela Internet no campo do jornalismo. Assim, na seção 2 apresenta-se algumas idéias de Anderson sobre a economia da Cauda Longa e na seção 3 enfoca-se as caudas longas que estão transformando o jornalismo, de acordo com um entrevista concedida por Anderson ao Press Gazette (STABE, 2006a). Por fim, são tecidas algumas considerações conclusivas sobre o assunto.

\section{A economia da Cauda Longa}

A Internet produziu transformações e oportunidades na economia. Segundo Brynjolfsson, Hu e Smith (2006), expandiu enormemente a variedade de produtos que podem ser produzidos, vendidos e comprados.

Para Anderson (2006), a Internet deu "origem a um novo universo, em que a receita total de uma multidão de produtos de nicho, com baixos volumes de vendas, é igual à receita total dos poucos grandes sucessos”.

Antes da Internet, os grandes sucessos de bilheteria eram as lentes através das quais se observava a cultura. A partir dela, o cenário mudou: os consumidores passaram a avançar em várias direções, a se dispersar ao 'sabor dos ventos', à medida que o mercado foi se fragmentando em inúmeros nichos (ANDERSON, 2006).

A Internet permitiu "acesso ilimitado e sem restrições a culturas e a conteúdos de todas as espécies, desde a tendência dominante até os veios mais remotos dos movimentos subterrâneos.” (ANDERSON, 2006, p. 3). Também 
permitiu que jornais e notícias, ao se tornarem digitais, apresentassem menores custos de produção, distribuição e venda (BRYNJOLFSSON; HU; SMITH, 2006).

Segundo Brynjolfsson, Hu e Smith (2006), do lado da produção, por exemplo, a CNN não precisa mais enviar um cinegrafista e um repórter para cobrir uma matéria em um lugar remoto, esperar para a matéria ser apurada e depois transmitida para uma estação de satélite. Agora a $\mathrm{CNN}$ pode enviar um repórter equipado com câmera, laptop e satellite phone (telefone móvel que se comunica usando satélites) e esse pode registrar, editar e transmitir a notícia em pouco tempo e com baixo custo.

Por outro lado, conforme Moraes (2005), com baixo custo e rapidez a Internet favoreceu a difusão extensiva de informações e conhecimentos, sem submetê-los às hierarquias de juízos e aos filtros ideológicos da mídia tradicional3.

Logo, a cultura, que antes vinha sendo fortemente influenciada pelos conglomerados de comunicação, passou a "um contínuo sem fronteiras de alto a baixo, com conteúdo amador e profissional competindo em igualdade de condições pela atenção" do usuário que "simplesmente escolhe aquilo de que gosta mais de um menu infinito" (ANDERSON, 2006, p. 3). Diante disso, Anderson (2006) conclui que a cultura está migrando de cultura de massa para cultura de nicho, uma vez que não se assiste mais aos mesmos filmes, assim como não se recebe mais notícias apenas pelos meios de comunicação social.

A maior variedade e volume de conteúdo na $W e b$ em relação a qualquer outra mídia é resultado da democratização das ferramentas de produção e do acesso cada vez mais universalizado, segundo Stevens e Rivas-Rodrigues (2007). Junto com a facilidade de publicar qualquer coisa na Internet, estes aspectos mudaram a história da mídia que vinha sendo de um consumo passivo. Atualmente, o leitor pode ser um consumidor passivo e, ao mesmo tempo, um criador de conteúdo (THE FUTURE, 2006).

A propósito, o poder dado ao leitor como criador e divulgador de conteúdo já mudou o cenário dos dados de acesso aos sites na Internet. Segundo o relatório

3 Pelo menos a curto prazo, este pressuposto de Moraes (2005) ainda pode ser considerado como relativamente correto, se considerado os pesados investimentos para se controlar a Internet. 
Future of Media (FUTURE, 2007), o You Tube que exibe filmes "domésticos" e a Wikipedia, enciclopédia on-line baseada no conhecimento coletivo de milhões de especialistas e semi-especialistas amadores, junto com o site da Apple são, respectivamente, os sites mais populares globalmente.

No passado não muito remoto, recorda Anderson (2006, p. 3), "quase os únicos lugares em que se podia escapar da tendência dominante eram as bibliotecas e as bancas de jornais. (...) praticamente as únicas fontes de cultura disponíveis”, além dos livros e das iniciativas de grupos de amigos que mal ultrapassavam as fronteiras de seus quintais.

Apesar de ainda existir demanda para a cultura de massa, Anderson (2006, p. 5) é enfático ao dizer que esse já não é mais o único mercado. "Os hits hoje competem com inúmeros mercados de nicho, de qualquer tamanho. $\mathrm{E}$ os consumidores exigem cada vez mais opções. A Era do tamanho único está chegando ao fim e em seu lugar está surgindo algo novo, o mercado de variedades”, prenuncia o autor.

A Cauda Longa, em síntese, "nada mais é que a cultura sem os filtros da escassez econômica" (ANDERSON, 2006, p. 51). Para Anderson (2006), quase todas as categorias de produtos se incluem na economia da Cauda Longa. A seguir descreve-se como a Cauda longa está transformando o jornalismo, segundo Chris Anderson (STABE, 2006a, 2006b).

\section{Efeitos da Cauda Longa no jornalismo}

A economia da abundância, vista pelo seu lado positivo, é vital para a democracia. Hoje, muito mais do que no passado, os indivíduos podem manifestar seu pensamento de forma rápida, fácil e praticamente sem custos. "O resultado é que o universo de conteúdo disponível hoje está crescendo mais rápido do que em nenhuma outra época." (ANDERSON, 2006, p. 52).

$\mathrm{Na}$ era da Internet, o indivíduo não está limitado ao que é divulgado pela mídia tradicional. Ele pode escolher entre uma variedade de opções. (ANDERSON, 2006). Além disso, pode produzir, recriar, difundir e compartilhar conteúdos de sua seleção (ROIG, 2006). Isto só foi possível graças à ausência de fronteiras e porque na 
Web a maioria dos meios não é institucionalizada, pertence a quem participa deles (RODRIGUES, 2006).

Roig (2006, p. 163) pontua que a internet redefiniu a relação entre produtores (tradicionalmente profissionais de criação e distribuição de conteúdo) e consumidores (tradicionalmente entendidos como receptores, espectadores). Para o autor, os consumidores deixaram de ser apenas usuários, "adquiriram a capacidade de converter-se em produtores ou editores, idealizando, selecionando, implementando e difundindo conteúdos próprios ou reelaborando e compartilhando conteúdos de sua seleção". O resultado disso é que na era digital, os meios emergentes e tradicionais se inter-relacionam e as barreiras se rompem entre recepção e emissão, produção e uso, comunicação de massa e comunicação interpessoal, entre profissional e amador, público e privado.

Ao referir-se a tal assunto, Rodrigues (2006, p. 64) afirma que "a proliferação dos blogs rompeu com o tradicional modelo emissor-receptor”. Hoje o leitor pode ser tanto um emissor quanto um receptor de informação. Daqui para frente, segundo ela, "a fronteira entre produzir e consumir informação esta[rá] cada vez mais diluída, mas ainda assim”, enfatiza, "o fenômeno do gatekeeping4 continua[rá] a ser fundamental” (2006, p. 173).

No cenário comunicacional está emergindo uma relação simbiótica entre a mídia tradicional (rádio, tevê e jornal) e a mídia social (blogs, podcasts e redes sociais on-line). Uma alimenta a outra, por exemplo, os blogs promovem fóruns para discutir o conteúdo divulgado na mídia e essa cita blogs e bloguistas, às vezes exclusivamente, assim como utiliza a discussão gerada nos blogs como fonte de idéias para sua pauta (FUTURE, 2006). Segundo Rodrigues (2006, p. 172), "há vários casos de informações veiculadas por blogs que foram aproveitadas pelos meios de comunicação social e há muitos blogs que são observadores atentos da actividade jornalística.”

A possibilidade de acessar notícias a qualquer hora, sobre qualquer assunto e de graça pode ser ótimo para os usuários da Internet, mas é um inferno para as empresas de notícias, na opinião de O’Reilly (2005). Segundo ele, o que incomoda a mídia tradicional, enquanto concorrente com os blogs, é o fato de que a concorrência

4 "Decisão sobre o que vai ou não ser publicado. Função do gatekeeper, editor ou conselho editorial." (LAGE, 2004, p. 57). 
é com a blogosfera (o mundo de todos os blogs) como um todo, pois não se trata apenas de uma competição entre sites, mas de uma competição entre modelos de negócio. Segundo Rodrigues (2006) e Peshin e Nachison (2006), enquanto o modelo de negócios e a organização do jornalismo tradicional concentram-se na emissão e na publicidade: valoriza-se "o rigoroso fluxo de trabalho editorial, a rentabilidade e a integridade", as comunidades ligadas em rede valorizam-se a discussão, a colaboração e a igualdade mais que a lucratividade.

Conforme Anderson (STABE, 2006a, 2006b), as duas caudas longas que estão transformando o jornalismo são: a Cauda longa do tempo (troca dos valoresnotícia através do tempo) e a Cauda Longa da abundância de conteúdo (representada pelos blogs, isto é, ao fato de que essas publicações pessoais competem com a mídia tradicional pela atenção do leitor).

\subsection{A Cauda Longa do tempo}

Nos jornais impressos o ciclo de vida das notícias é de 24 horas (DEZSÖ et al., 2006). Depois disso, "os jornais se transformam em embrulho de peixe" (ANDERSON, 2006, p. 141).

$\mathrm{Na}$ Web, apesar de as notícias ficarem velhas depois de 36 horas - esse é o tempo médio que metade de todos os leitores de uma notícia demoram para acessá-la -, as notícias de relevância duradoura podem ser lidas a longo prazo (STABE, 2006a; DEZSÖ et al., 2006; COHEN, 2006). Armazenadas e disponíveis em arquivos digitais, as notícias podem ser encontradas via mecanismos de busca ou acessadas mediante recomendações produzidas por sistemas de recomendação5 (ANDERSON, 2006; DEZSÖ et al., 2006).

Segundo Dezsö et al (2006), na mídia on-line o fluxo contínuo de notícias freqüentemente destrói uma notícia dentro de horas por conta da limitação de espaço. Em outras palavras, as notícias adicionadas vão sendo gradualmente

5 Aplicações incorporadas nos sites. Burke (2002, p. 1), define sistemas de recomendação como quaisquer sistemas que produzem "recomendações individualizadas como entrada ou que tem o efeito de guiar o usuário em um caminho personalizado para objetos interessantes e úteis em um espaço amplo de possíveis opções”. 
removidas da página principal e das subcategorias que pertencem em poucas horas, depois disso, frequentemente ficam disponíveis em arquivos digitais.

As notícias acessadas via mecanismos de busca, segundo Anderson (apud STABE, 2006a), podem emergir novamente da Cauda Longa. Conforme pontua, nos registros de acesso dos sites de notícias que possuem arquivos on-line abertos é encontrada uma das caudas longas do jornalismo.

Individualmente, para Anderson (apud STABE, 2006a), cada notícia arquivada é acessada raramente depois de 36 horas, mas coletivamente, pode totalizar um número significativo de leitores. Por isso, acredita que relevância de longo-prazo e confiabilidade podem ser considerados como importantes valoresnotícia na Web.

Na Web, ao contrário da mídia impressa, a relevância de uma notícia não é determinada pelo lugar em que é disponibilizada na página, mas pelo que as pessoas pensam dela (ANDERSON, 2006). Isso vem ao encontro do que diz O’Reilly (2005). Para ele, na Web quem decide o que é importante é a audiência, não os meios de comunicação tradicionais.

Nesta perspectiva, a notícia considerada boa cria links remetentes através do tempo. Conforme Anderson (2006, p. 141-142),

depois que o conteúdo sai da primeira página do site, sua popularidade despenca. Mas como o acesso aos sites é impulsionado cada vez mais pelo Google, esta regra está sendo rompida.

O Google não chega a ignorar o tempo, mas ele efetivamente mede a relevância sobretudo com base nos incoming links ou links remetentes, isto é, aqueles que remetem a determinado site, não em função da novidade. Assim, ao pesquisar um termo, é provável que se encontre a melhor página, não a mais nova. E como as páginas mais antigas tem mais tempo para atrair links remetentes, elas às vezes desfrutam de vantagem em relação às mais [novas]. $\mathrm{O}$ resultado é que a costumeira queda de popularidade dos novos lançamentos em blogs e das páginas de notícias on-line é hoje muito mais gradual do que no passado, graças à intensidade do tráfego proveniente de pesquisas. O Google sob certo sentido atua como máquina do tempo, e estamos começando a medir o efeito daí decorrentes sobre as editoras, a propaganda e a atenção.

Para Anderson (apud STABE, 2006b), uma vez que os arquivos digitais podem ser acessados via mecanismos de busca, as notícias de relevância duradoura 
irão, a longo prazo, se tornar mais valiosas que as notícias de Última Hora, as chamadas Breaking News. Com isso, Anderson conclui que uma troca nos valoresnotícias provavelmente pode acontecer.

Steves e Rivas-Rodriguez (2007), acreditam que o conteúdo jornalístico tende a ser consumido após o estágio Breaking News de entrega. Isto é conseqüência, para eles, do baixo custo de produção e da economia de busca, entendida como a habilidade de navegar facilmente através das hierarquias de escolhas.

Para Steves e Rivas-Rodriguez (2007), os custos de armazenamento e distribuição no jornalismo on-line são extremamente baixos comparados à mídia tradicional. Assim, os meios de comunicação que armazenam seu conteúdo em arquivos têm uma 'arca do tesouro virtual' de informação e materiais de referência, uma vez que a Cauda Longa e a economia de busca podem ajudar o jornalismo online a tornar o conteúdo mais relevante, isto é, mais significativo para o usuário, aumentando, conseqüentemente, o tráfico nos sites.

Sites jornalísticos que fecham seus arquivos para o público operam contra os princípios da Cauda Longa e da economia de busca, porque ao invés de promover o tráfico em seus sites, acabam levando o usuário a procurar na Web pelo conteúdo que estavam interessados em ler (STEVES; RIVAS-RODRIGUEZ, 2007). Segundo Steves e Rivas-Rodriguez (2007), Battle ilustrou esse problema quando mencionou porque o Wall Street Journal e o Economist estavam despencando nas listas de leitura de seus usuários on-line.

\subsection{A Cauda Longa da abundância de conteúdo}

A grande mídia continua a dominar a pequena cabeça do mercado de massa, mas o crescimento de milhões de blogs representa uma importante Cauda Longa (STABE, 2006), visto que "o número de autores e leitores de blogs tem aumentado, assim como as fontes de informação” (RODRIGUES, 2006, p. 49).

Só para se ter uma idéia, em abril de 2006, o número de blogs rastreados pelo site Technorati era de 35,4 milhões. Um ano depois, esse número já ultrapassa 70 milhões. O número de blogs não pára crescer, assim como não pára de aumentar o número de blogs entre os 100 sites mais populares: em outubro de 2006, 12 blogs 
estavam na lista dos 100 sites mais populares. Em abril de 2007, são 22 blogs na lista. (THE STATE, 2007).

Segundo o site Technorati (THE STATE, 2007), estes números evidenciam a contínua maturação da blogosfera. Pesquisas desse site indicam que é cada vez menos provável que os usuários distingam um blog de um jornal on-line tradicional, por exemplo, o nytimes.com, pois para uma quantidade cada vez maior de usuários, tanto blogs como sites de empresas da mídia são sites de notícias, informação, entretenimento, fofoca, etc.

Uma justificativa para este fato é dada por Anderson (2006, p. 184). Para ele, existe pouca diferença entre jornalismo profissional e reportagem amadora, visto que em suas áreas de interesse, "os bloguistas geralmente sabem tanto quanto ou mais que os jornalistas".

Para Lowrey (2006), a diferença fundamental entre blogs e jornalismo se refere à organização da produção. Diferença em conteúdo, processo de trabalho, tom, valores e formato são, para o autor, sintomas dessa diferença estrutural subjacente. Só para exemplificar, os blogs têm como características a participação do usuário, a transparência e o tom opinativo, ao passo que os valores tradicionais do jornalismo são precisão, imparcialidade e objetividade (LOWREY, 2006).

Para Rodrigues (2006, p. 50), os blogs e o jornalismo "são duas áreas distintas, que não devem ser confundidas, apesar de poderem ser complementares ou até alternativas." Conforme pontua a autora,

Os blogs são um meio que pode ser utilizado para os mais diversos fins e nesse âmbito podem ser utilizados para publicação de um diário pessoal, para a exposição de opiniões, para a divulgação de fotografias e até para a prática jornalística. Mas o jornalismo é uma actividade profissional, que deve obedecer a regras específicas em qualquer meio em que seja exercida. Por isso mesmo, a definição de jornalismo depende de muitos factores normalmente ligados a esta actividade profissional. "Na sua essência, corresponde, dominantemente, à actividade de divulgação mediada, periódica, organizada e hierarquizada de informações com interesse para o público.

A partir de algumas características do jornalismo, o Quadro 1 apresenta aspectos fundamentais que diferenciam o jornalismo da blogosfera. 


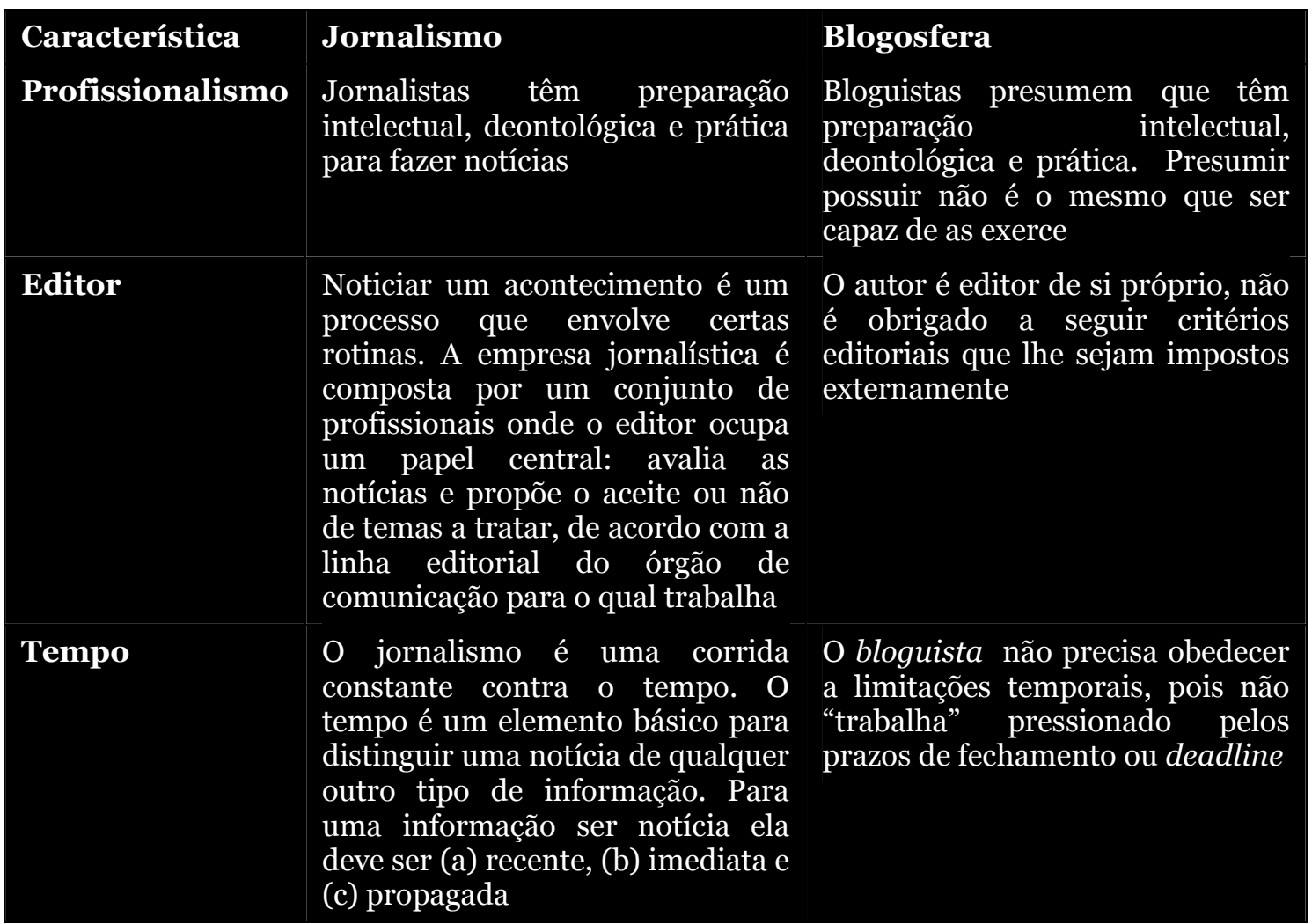

Quadro 1 - Aspectos fundamentais que diferem o jornalismo da blogosfera.

Fonte: Adaptado de Rodrigues (2006, p. 51-55).

O relatório Future of Media (FUTURE, 2006), apresenta as característicaschave da mídia tradicional e da mídia social (blogs, podcast e redes sociais on-line). Essas podem ser analisadas no Quadro 2. 


\section{Mídia Social}

Conversação é quase sempre definida pelo mais importante da mídia social

Relações entre pessoas e idéias emergem de uma maneira muito diferente da configuração um-para-muitos da mídia de massa

Anotação consiste em comentário e referência para informações e idéias existentes. Espalha-se logo dentro da anotação geoespacial, onde conversações são geradas por localizações físicas

Auto-exposição é o mais poderoso veículo da mídia social para a auto-expressão. $\mathrm{O}$ exibicionismo e o voyeurismo associado dos blogs e das redes sociais são fatores-chave em direção a participação

\section{Mídia Tradicional}

Acesso é uma característica distintiva da mídia tradicional, cujos representantes, em virtude de sua posição e influência, podem estender $\mathrm{o}$ acesso praticamente aonde eles desejam

Habilidades de produção são extremamente altas, com base em investimento de capital e conhecimento especializado

Consistência de produção e garantia de qualidade são desejáveis, junto com a confiança

Profissionalismo como uma característica da mídia tradicional divide em - (1) critérios e grau elevado de talento, (2) uma caixa que amadores podem facilmente pisar fora para inovar

Quadro 2 - Características-chave da mídia social e da mídia tradicional.

Fonte: Traduzido de Future of Media (2006).

Como se percebe, com base em Lowrey (2006), Rodrigues (2006) e no relatório Future of Media (FUTURE, 2006), o trabalho jornalístico é cercado por rigor, ética e profissionalismo enquanto que o trabalho de um bloguista nem sempre é pautado nestas características.

Mesmo assim, "os blogs alcançaram os clientes da grande mídia um a um, encaixando-se em nichos ainda mais específicos do que seus precursores da velha mídia." (POSNER apud ANDERSON, 2006, p. 184). Uma justificativa dada para este fato vem de Rodrigues (2006, p. 57). Segundo a autora, "há áreas na blogosfera onde têm aparecido autênticos especialistas, como seja o caso da tecnologia, da arte e do cinema, que abordam os temas com mais profundidade que muitos jornais"

Atualmente, a grande mídia e os blogs competem por atenção on-line e, cada vez mais, pelas receitas publicitárias (ANDERSON apud STABE, 2006) Por isso, os blogs representam uma ameaça evidente para o jornalismo.

Tentando contornar essa ameaça, empresas jornalísticas começam a oferecer blogs em seus sites. Além disso, jornalistas têm falado publicamente sobre a 
necessidade de agregar blogs ao jornalismo ou adotá-los como uma ferramenta de pesquisa e apresentação de notícias e checagem dos fatos. Neste intento, menciona-se ainda a adoção do jornalismo cívico6, a adoção de ombudsmem e o crescimento do uso de fontes não oficiais como tentativas de resposta a ameaça das publicações pessoal, em particular, dos blogs (LOWREY, 2006).

Para Rodrigues (2006) "os blogs não devem ser vistos tanto como uma ameaça aos meios tradicionais, mas mais como um conjunto de novas possibilidades, onde tem que haver necessariamente alguns cuidados.” (2006, p. 177).

\section{CONSIDERAÇõES FINAIS}

Em plena era da "comunicação quântica" as notícias existem em um espaço virtual, inventadas por diferentes fontes, de tal forma que cada observador, de acordo com as suas características, sua história de escolhas passadas, faz com que a apresentação das mesmas se dê de forma individualizada.

Para quem atua no negócio de notícias, a economia da abundância levanta algumas questões problemáticas sobre o futuro da área, uma vez que a divulgação de notícias e informações não mais pertencem ao domínio dos profissionais da comunicação.

Considerando que a Internet revolucionou o processo de comunicação e o fluxo de informação, bem como vem transformando a forma de fazer jornalismo, conclui-se que os meios de comunicação, segundo o modelo que se conhece hoje, deixarão de existir nos próximos anos. Em seu lugar, aparecerá um novo modelo comunicativo, baseado na participação dos usuários, conforme prevê Lowrey (2006).

\footnotetext{
6 Também conhecido como jornalismo cidadão, jornalismo público, novo jornalismo, jornalismo comunitário, entre outros. "Difere do modelo dominante de jornalismo por se concentrar no problema de pessoas comuns, nas suas preferências quanto aos assuntos, e no fornecimento de informação que é de importância prática para aqueles que estão interessados em envolver-se activamente no processo político" (EKSTEROWICZ; ROBERTS; CLARK, 2003 apud RODRIGUES, 2006, p. 100).
} 


\section{REFERÊNCIAS}

ANDERSON, Cris. A Cauda Longa: do mercado de massa para o mercado de nicho. Trad. Afonso Celso da Cunha Serra. Rio de Janeiro: Elsevier, 2006.

BRYNJOLFSSON, Erik; HU, Yu (Jeffrey); SMITH, Michael D. From Niches to Riches: Anatomy of the Long Tail. MITSloan Management Review, v. 47, n. 4, p. 67-71, 2006. Disponível em: <http://www.viewswire.com/report_dl.asp?mode=fi\&fi=1740754759.PDF $>$. Acesso: 2 ago. 2007.

BURKE, Robin. Hybrid recommender systems: Survey and experiments. User Modeling and User Adapted Interaction, v.12, n. 6, p. 331-370, nov. 2002. Disponível em: <http://josquin.cti.depaul.edu/ rburke/pubs/burkeumuaio2.pdf $>$. Acesso em: 28 dez. 2006.

CASTELLS, Manuel. Internet e sociedade em rede. In: MORAES, Dênis (Org.). Por uma outra comunicação: mídia, mundialização cultural e poder. 3. ed. Rio de Janeiro: Record, 2005.

COHEN, Noam. Notícias têm "vida útil" mais longa na internet: Pesquisa mostra que reportagens continuam a ser bem acessadas por até 36 horas após a sua publicação na rede. O Estado de S. Paulo. São Paulo, 24 jul. 2006. Disponível em:

<http://www.link.estadao.com.br/index.cfm?id_conteudo=8066>. Acesso em: 19 mar. 2007.

DEZSÖ, Z. et al. Dynamics of information access on the web. The American Physical Society E (Statistical, Nonlinear, and Soft Matter Physics), v. 73, n. 6, 30 jun. 2006. Disponível em: <http://link.aps.org/abstract/PRE/v73/eo66132>. Acesso em: 19 mar. 2007.

GILLMOR, Dan. Blogueiros inovam na comunicação. A mídia emergente.

Departamento de Estado dos EUA, março de 2006. v. 11, n. 2, p. 24-26.

Disponível em:

<http://usinfo.state.gov/journals/itgic/o306/ijgp/ijgpo306.pdf>. Acesso em: 17 ago. 2007.

GILLMOR, Dan. We the media. CA, USA: O'Reilly Media, Inc., 2004. Disponível em: <http://www.oreilly.com/catalog/wemedia/book/>. Acesso em: 17 ago. 2007.

LAGE, Nilson. Estrutura da Notícia. 5. ed. São Paulo: Ática, 2004.

LOWREY, Wilson. Mapping the journalism-blogging relationship. Journalism, v. 7, n. 4, 2006, p. 477-500. Disponível em:

<http://jou.sagepub.com/cgi/content/abstract/7/4/477>. Acesso em: 27 mar. 2007.

MORAES, Dênis. O capital da mídia na lógica da globalização. In: MORAES, Dênis (Org.). Por uma outra comunicação: mídia, mundialização cultural e poder. 3. ed. Rio de Janeiro: Record, 2005.

O'REILLY, Tim. What Is Web 2.o - Design Patterns and Business Models for the Next Generation of Software. O'Reilly Publishing, 2005. Disponível em: 
<http://facweb.cti.depaul.edu/jnowotarski/se425/What\%20Is\%2oWeb\%202 \%20point\%200.pdf >. Acesso em: 10 mar. 2007.

\section{Burocrat}

as

PESKIN, Dale; NACHISON, Andrew. A Mídia Emergente Reestrutura a Sociedade Global. A mídia emergente. Departamento de Estado dos EUA, março de 2006. v. 11, n. 2, p. 4-6. Disponível em: <http://usinfo.state.gov/journals/itgic/o306/ijgp/ijgpo306.pdf>. Acesso em: 17 ago. 2007.

POSTER, Mark. Cidadania, mídia digital e globalização. In: MORAES, Dênis (Org.). Por uma outra comunicação: mídia, mundialização cultural e poder. 3 . ed. Rio de Janeiro: Record, 2005.

RODRIGUES, Catarina. Blogs e a fragmentação do espaço público. 2006. Disponível em: <www.labcom.ubi.pt/livroslabcom/pdfs/rodrigues-catarina-blogsfragmentacao-espaco-publico.pdf $>$. Acesso em: 15 mar. 2007.

ROIG, Antoni. iProdúcete a ti mismo! Televisión, internet y la emergencia de la cultura de clip. 2006. Disponível em:

<http://www.zemos98.org/festivales/zemos988/pack/produceteatimismo_la televisionnolofilma.pdf $>$. Acesso em: 5 março, 2007.

STABE, Martin. Is long tail 'hitism'causing journalists' negative view blogs? 2006b. Disponível em:

<http://www.martinstabe.com/journalism/viewarticle.php?story=22>.

Acesso em: 6 mar. 2007.

STABE, Martin. Journalist should understand "Long Tails". 2006a.

Disponível em:

<http://www.pressgazette.co.uk/article/o70906/journalists_should_underst and_long_tails $>$. Acesso em: 6 mar. 2007.

STEVENS, Richards; RIVAS-RODRIGUES, Maggie. Making History Useful: The long Tail, the Search Economy na de U.S. Latino \& Latina World War II Oral History Project Web Site. In: INTERNATIONAL SYMPOSIUM ON ONLINE JOURNALISM, 2007, Texas. Disponível em:

<http://journalism.utexas.edu/onlinejournalism/2007/papers/Stevens.pdf >. Acesso em: 1 ago. 2007.

THE FUTURE OF MEDIA: REPORT 2006. Disponível em: <http://www.futureexploration.net/fomo6/Future_of_Media_Report2006.p df $>$. Acesso em: 2 ago. 2007.

THE FUTURE OF MEDIA: REPORT 2007. Disponível em: <http://www.rossdawsonblog.com/Future_of_Media_Report2007.pdf>. Acesso em: 2 ago. 2007.

THE STATE of the live web, abril 2007. Disponível em: <http://www.technorati.com/weblog/>. Acesso em: 13 abril 2007. 